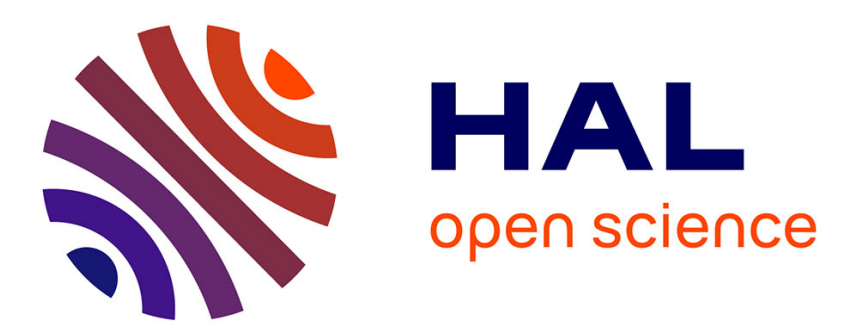

\title{
Experimental Verification of a Semi-Empirical V/STOL Aircraft Performance Analysis Method
}

\author{
Murat Bronz, Antoine Drouin
}

\section{To cite this version:}

Murat Bronz, Antoine Drouin. Experimental Verification of a Semi-Empirical V/STOL Aircraft Performance Analysis Method. AIAA Aviation 2016, 34th AIAA Applied Aerodynamics Conference, Jun 2016, Washington, United States. pp.eISBN: 978-1-62410-437-4, 10.2514/6.2016-3410 . hal01333873

\section{HAL Id: hal-01333873 \\ https://hal-enac.archives-ouvertes.fr/hal-01333873}

Submitted on 24 Jun 2016

HAL is a multi-disciplinary open access archive for the deposit and dissemination of scientific research documents, whether they are published or not. The documents may come from teaching and research institutions in France or abroad, or from public or private research centers.
L'archive ouverte pluridisciplinaire $\mathbf{H A L}$, est destinée au dépôt et à la diffusion de documents scientifiques de niveau recherche, publiés ou non, émanant des établissements d'enseignement et de recherche français ou étrangers, des laboratoires publics ou privés. 


\title{
Experimental Verification of a Semi-Empirical V/STOL Aircraft Performance Analysis Method
}

\author{
Murat Bronz ${ }^{*}$ and Antoine Drouin ${ }^{\dagger}$ \\ ENAC, F-31055 Toulouse, France \\ University of Toulouse, F-31400 Toulouse, France
}

\begin{abstract}
Verification of a previously developed semi-empirical Vertical/Short Takeoff and Landing (V/STOL) aircraft performance analysis program is discussed. The proposed method uses actuator disk theory for the propeller slipstream velocity calculations starting from an input thrust. Semi-empirical formulations are used in order to estimate the forces and moments generated by the highly coupled propeller and wing interaction. The main objective of this study is to compare the results of the method with existing experimental measurement and determine the validity to use this method of calculation for the design optimization of $\mathrm{V} / \mathrm{STOL}$ vehicles. Two existing NASA experiment cases are investigated and compared.
\end{abstract}

\section{Introduction}

V/STOL aircrafts offers unique mission characteristics with wide-speed flight envelope. Several configurations of V/STOL exists, and for a long time there have been an idea of distributing the propulsion system over the wings in order to enhance the performance. The idea of Distributed Electric Propulsion (DEP) was not feasible previously, where reciprocating and turbine engines used simply did not make it possible to practically build the vehicles. However, the possibility of using a DEP system has been widely investigated ${ }^{1-3}$. Recently, with the improvements on the electric propulsion systems, the use of electric system makes it possible to design an airframe that is well integrated with the propulsion system ${ }^{4}$ in order to achieve big aerodynamic performance improvements.

*Assistant Professor on Applied Aerodynamics, MAIAA, ENAC UAV Lab, F-31055 Toulouse, France

${ }^{\dagger}$ Assistant Professor on Flight Control and Dynamical Systems, MAIAA, F-31055 Toulouse, France 

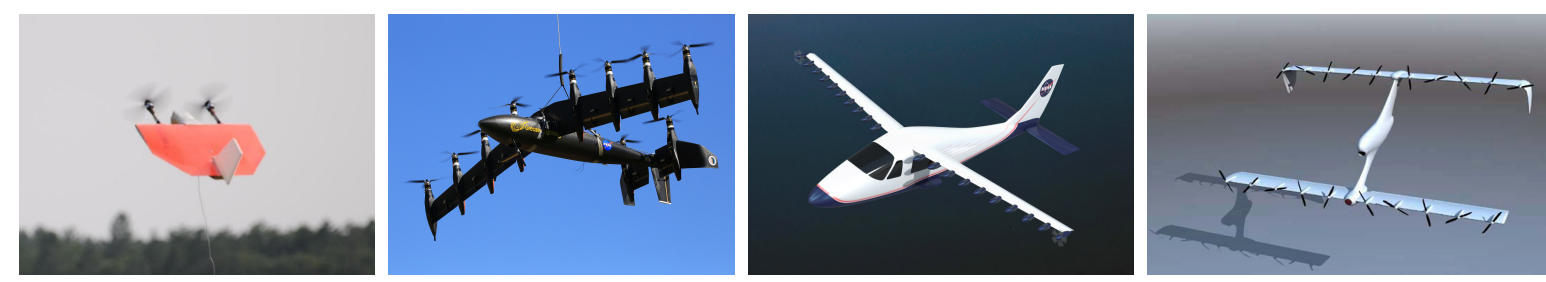

Figure 1. Tilt-Body micro air vehicle $M A V I O N$ from ISAE, a small demonstrator of NASA's $G L-10$, the LEAPTech Program from JobyAviation, and the Pterosaur from ONERA.

LEAPTech, ${ }^{5}$ shown in Figure 1, is a good example of a highly-DEP configuration. The complete wing is immersed inside the distributed propeller slipstream which increases the dynamic pressure over the wing. This results a significant wing surface reduction which makes the aircraft more efficient during the cruise flight conditions as the drag caused by the unnecessary wing surface that is needed only for the take-off and landing conditions is reduced. The V/STOL configuration with DEP is also interesting on the small scale, such as ISAE's tilt-body MAVION, which is a good example of a hand-release vertical take-off and afterwards transition to cruise flight concept. The GL-10, also shown in Figure 1, that is capable of vertical take-off by tilting its wing and then transition for an efficient cruise by adapting its multiple propellers located on the leading edge of the wing. Finally, the Pterosaur from ONERA is shown as an example for unconventional use of DEP system.

\section{A. Problem Definition}

The design of the mentioned configurations requires a good understanding of the interaction between the DEP system and the airframe. The propeller wing interaction is highly complex to solve without simplifications. Jameson ${ }^{6}$ has developed semi-empirical formulations in order to estimate the force and moment generation on V/STOL vehicles which is the basis of the used method in this study. The inclined propeller forces are estimated based on De Young's method. ${ }^{7}$

\section{B. Present Work}

Comparison with previous experimental measurements from NASA are presented following the brief explanation of the semi-empirical method that is used for the analyses. Last part of the paper discusses the intended use and the limits of the method.

\section{Aerodynamic Model for Propeller Wing Combination}

The semi-empirical estimation method of forces and moments of a propeller wing combination will be described briefly here for the consistency of the paper, interested readers should refer to the basis of the method by Jameson, ${ }^{6}$ and with additional moment and viscous drag contribution to Bronz and Drouin. ${ }^{8}$ An arbitrary number of propeller slipstreams is defined, 
with individual thrust, actuator disk area, position and orientation. The method is mainly based on momentum theory, so that the swirl effects of the propeller slipstream are not modeled. Inclined propeller thrust is estimated by DeYoung's method.

\section{A. Propeller Forces}

The propeller forces are modeled according to actuator disk theory, for a given propeller thrust $T$, the ratio $\mu$, between the free stream $V_{\infty}$ and propeller jet slipstream $V_{j}$, for a given actuator area of $S_{p}$ is given by

$$
\mu=\frac{V_{\infty}}{V_{j}}=\sqrt{1-\frac{T}{0.5 \rho V_{j}^{2} S_{p}}}
$$

Each individual slipstream is taken as circular form, and their contraction is estimated with

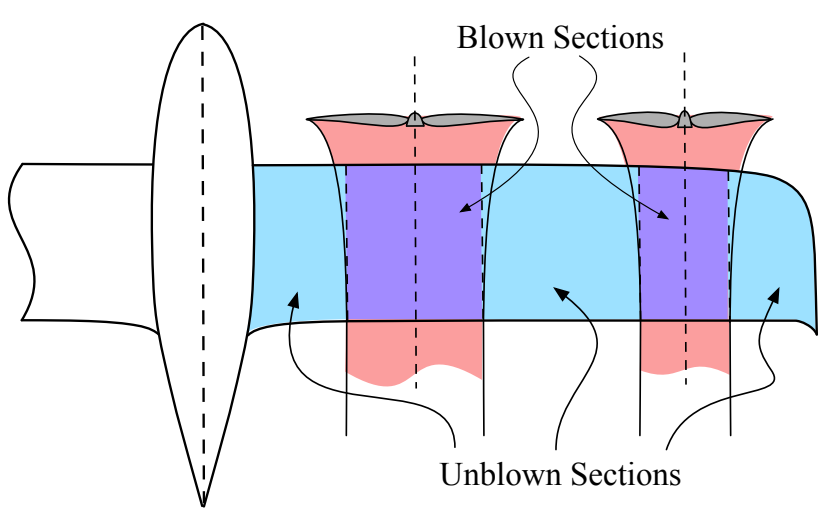

Figure 2. Showing the creation of wing sections according to the fully developed propeller slipstream width. Note that for each thrust value the sections will dynamically be changed in order to take into account the contraction.

$$
b_{p c}=b_{p} \sqrt{\frac{1+\mu}{2}}
$$

where, $b_{p}$ is the propeller disk diameter or width, and $b_{p c}$ is the fully developed contracted slipstream diameter or width. Once the contracted slipstream diameter is calculated, the wing can be separated into sections, as shown in Figure 2, that are inside the propeller slipstream or outside. Note that the propeller slipstream is taken as fully developed for simplification reasons.

Inclined propellers will deflect the free stream, which will change the angle of attack of the wing inside this slipstream. This downwash $\epsilon$ can be determined according to the inflow angle of the propeller $\alpha_{j}$ as $\epsilon=E \alpha_{j}$ according to Ribner ${ }^{9}$ and De Young. ${ }^{7}$

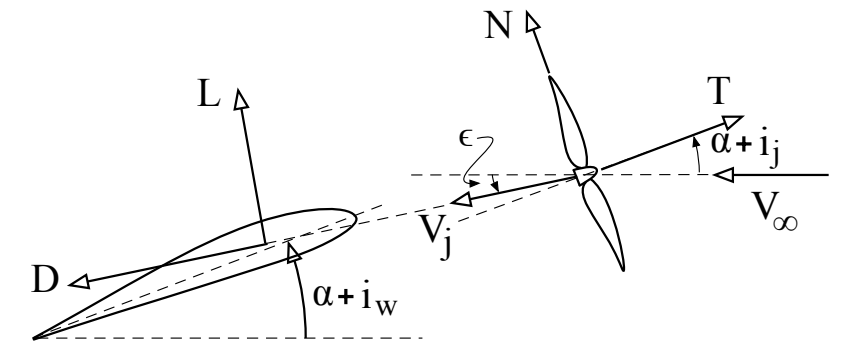

Figure 3. Shows the wing incidence angle $i_{w}$, jet incidence angle $i_{j}$, angle of attack of the fuselage $\alpha$ with the resultant lift $L$, drag $D$, thrust $T$ and the propeller normal force $N$, propeller downwash $\epsilon$, jet slipstream $V_{j}$. 


\section{B. Actuator Inflow Angle Change due to Wing, Fuselage and Other Propeller Jets Upwash}

Each actuator will be influenced by the fuselage, wing, and the other propeller jets. Taking these into effect, the inflow angle for each jet will be the sum of

$$
\alpha_{j}=\alpha+i_{j}+U_{w}\left(\alpha+i_{w}\right)+U_{f} \alpha+\sum_{\text {otherjets }} U_{o_{j}} \epsilon
$$

where, $U_{w}$ is the upwash due to wing, $U_{f}$ is the upwash due to fuselage and $U_{0_{j}}$ is the upwash due to the other propeller slipstreams.

For each propeller slipstream,$\alpha_{j}$ can be written as

$$
\begin{aligned}
& \alpha_{j 1}=\alpha+i_{j_{1}}+U_{w}\left(\alpha+i_{w}\right)+U_{f} \alpha+U_{o j_{12}} \epsilon_{2}+\cdots+U_{o j_{1 n}} \epsilon_{n} \\
& \alpha_{j 2}=\alpha+i_{j_{2}}+U_{w}\left(\alpha+i_{w}\right)+U_{f} \alpha+U_{o j_{21}} \epsilon_{1}+\cdots+U_{o j_{2 n}} \epsilon_{n} \\
& \alpha_{j 3}=\alpha+i_{j_{3}}+U_{w}\left(\alpha+i_{w}\right)+U_{f} \alpha+U_{o j_{31}} \epsilon_{1}+\cdots+U_{o j_{3 n}} \epsilon_{n} \\
& \quad \vdots \\
& \alpha_{j n}=\cdots
\end{aligned}
$$

for a half wing with $n$ propellers mounted on the leading edge. $U_{o j_{12}}$ presents the upwash effect of the second actuator on the first one. As long as there is a fuselage between the propellers separating the slipstreams, the upwash effects coming from the other wing can be neglected. Substituting $\epsilon$ from $\epsilon=E \alpha_{j}$, results a set of linear equations in the form of $A x=b$.

Once the set of linear equations solved, $\epsilon$ and therefore the inflow angles $\alpha_{j}$ can be found. Similarly, wing inflow angles for sections that are inside the freestream and that are inside the propeller slipstream will be

$$
\alpha_{w_{j 1}}=\alpha+i_{w}+U_{f} \alpha \quad \text { and } \quad \alpha_{w_{j \mu}}=\alpha_{w_{j 1}}-\epsilon+\sum_{j e t s} U_{\infty_{j}} \epsilon
$$

Propeller normal force can be calculated with the assumption of being proportional to inflow angle $\alpha_{j}$ as in $C_{N}=C_{N_{\alpha}} \sin \alpha_{j}$.

Resulting Lift Slope in a Slipstream is a function of the influenced mass flow around the wing. The essential difference between a wing in free stream of speed $V_{\infty}$, and a stationary wing immersed in a slipstream of the same speed $\mathrm{V}$, is the reduction of the mass flow outside the slipstream and also a reduction in the mass flow influenced by the wing. The wing in

free stream is influenced from a mass flow that is passing through a tube surface $S_{\infty}$ of 
$\pi b^{2} / 4$ containing the wing tips. However, the wing in a slipstream passing through surface $S_{j}$ influences a smaller mass flow resulting a reduction in the effective span or aspect ratio of the wing.

In the case of a stationary wing immersed in a slipstream, compared to a wing in free stream, the same amount of lift has to be generated by deflection of a smaller mass flow through a greater downwash angle. Assuming that the additional downwash angle due to the slipstream is a constant fraction of the downwash of the wing in free stream, with a value of $\mathrm{p}$, then the Aspect Ratio (AR) reduces to

$$
A R_{0}=\frac{A R}{1+p}
$$

\section{Partially Immersed Wing in Arbitrary Number of Slipstreams}

The slipstream over the wing will be generated by individual propellers, and also there will be different propulsion configurations for different flight phases, hence an approximation in order to calculate the highly complex force, moments, and interactions. A simple estimation can be made by superposition of forces over the wing in free stream and the individual parts that are immersed in slipstreams. The individual parts that are immersed in slipstream are calculated as isolated planforms. Thus, the additional increase on each isolated planform will simply be the difference between the planform in free stream $V_{\infty}$, and the planform immersed in a jet slipstream $V_{j}$ moving with a forward speed of $V_{\infty}$. The difference in lift will be

$$
\Delta L=\frac{1}{2} \rho S_{w_{j}}\left(V_{j}^{2} C L_{\alpha_{j \mu}} \alpha_{w_{j \mu}}-V_{\infty}^{2} C L_{\alpha_{\infty}} \alpha_{w_{j \infty}}\right)
$$

where $C L_{\alpha_{j \mu}}$ is the lift slope of the wing part that is inside the jet slipstream with a velocity ratio of $\mu=V_{\infty} / V_{j}$ by taking the aspect ratio as $b_{j} / S_{w_{j}} . C L_{\alpha_{\infty}}$ is the lift slope of the same wing part in a freestream, or in other words when $\mu=1, \alpha_{w_{j \mu}}$ is the angle of attack of the wing in jet slipstream, and $\alpha_{w_{j_{\infty}}}$ is the angle of attack of the same part in free stream. It should be noted that the angle of attack of the wing portion in jet slipstream is reduced compared to the angle of attack in the free stream by the slipstream downwash of $\epsilon$. Additionally, an inclined slipstream to the free stream will generate an external upwash, which can be approximated by assuming the slipstream as a falling cylinder model. The upwash at a distance $y$ from the center axis of the slipstream is $\epsilon b_{j}^{2} / 2 / y^{2}$

According to ${ }^{6}$ the average upwash over the external part of the wing will approximately be $\frac{S_{w_{j}}}{S} \epsilon$. Taking all upwash effects of propeller jets, the increase in lift can be calculated by multiplying the sum of all slipstream upwash angle with the unblown surface area and 
the lift slope of the complete wing in freestream $C L_{\alpha_{\infty}}$ For the small angle of attack, lift

force generated by the wing can be found by adding up the freestream lift of the complete wing, the additional lift created from the unblown parts of the wing because of the upwash effects of the jets, and finally the additional lift on the blown sections coming from dynamic pressure increase because of the jet velocities.

$$
L=0.5 \rho V_{\infty}^{2} S C L_{\alpha_{\infty}}+0.5 \rho V_{\infty}^{2} S C L_{\alpha_{\infty}}\left(S-\sum_{j e t s} S_{w_{j}}\right) \sum_{j e t s} \frac{S_{w_{j}}}{S} \epsilon+\sum_{j e t s} \Delta L_{j}
$$

A similar approach can be used to calculate the additional induced drag for the wing section that are inside the slipstream. $\Delta D_{i}$ can be calculated as the freestream lift of this section multiplied by the change in induced downwash angle, plus the new induced downwash angle multiplied by the change in the lift $\Delta L$.

$$
\Delta D_{i}=0.5 \rho V_{\infty}^{2} S_{w_{j}} C L_{j_{\infty}}\left(\alpha_{i_{j}}-\alpha_{i_{\infty}}\right)+\Delta L \alpha_{i_{j}}
$$

Finally, induced drag $D_{i}$ can be found by summing up the induced drag of the whole wing in freestream as if there were no propeller slipstreams on it, and the additional induced drag $\Delta D_{i}$

$$
D_{i}=0.5 \rho V_{\infty}^{2} S k C L_{\infty}^{2}+\sum_{j e t s} \Delta D_{i_{j}}
$$

It should be noted that each wing section inside the propeller slipstream generates a lift force perpendicular to the local flow velocity and the drag force parallel to flow velocity. Therefore they should be rotated back by the propeller slipstream downwash angle $\epsilon$ and then summed in order to obtain the total lift force $L_{\infty}$ and drag force $D_{\infty}$.

\section{Effect of Flaps}

The effect of flaps are modeled by an increase on the wing angle of attack as presented by Jameson. ${ }^{6} \alpha / \delta_{\infty}$ being the flap effectiveness of three dimensional wing in free stream, effective wing incidence angle $i_{w_{\infty}}$ becomes

$$
i_{w_{\infty}}=i_{w}+\alpha / \delta_{\infty} \delta_{f}
$$

where $\delta_{f}$ is the flap deflection and,

$$
\alpha / \delta_{\infty}=\frac{\sqrt{\alpha / \delta_{2 D}}+\alpha / \delta_{2 D} \frac{A R+4.5}{A R+2} A R}{\sqrt{\alpha / \delta_{2 D}}+\frac{A R+4.5}{A R+2} A R}
$$


Likewise for a wing section inside propeller slipstream, effective wing incidence $i_{w_{j \mu}}$ becomes

$$
i_{w_{j \mu}}=i_{w}+\alpha / \delta_{j \mu} \delta_{f}
$$

\section{Total Forces and Moments}

\section{A. Forces}

For now, only longitudinal flight dynamics is considered, so that the lateral force and moments are assumed to be zero $F_{y}=M_{x}=M_{z}=0$ as in equilibrium. Contribution of the wing lift $L_{\infty}$, drag $D_{\infty}$, propeller thrust $T$, and propeller normal force $N$ will be taken into account as

$$
\begin{aligned}
& F_{z}=L_{\infty}+\sum_{j e t s} T \sin \left(\alpha+i_{j}\right)+\sum_{j e t s} N \cos \left(\alpha+i_{j}\right) \\
& F_{x}=D_{\infty}-\sum_{j e t s} T \cos \left(\alpha+i_{j}\right)+\sum_{j e t s} N \sin \left(\alpha+i_{j}\right)
\end{aligned}
$$

\section{B. Moment}

The pitching moment is calculated by the resultant wing forces and moments as well. However, as the aircraft is capable of increasing its pitch attitude up to 90 degrees, the moment arm between the wing aerodynamic center and the center of gravity of the aircraft changes during this rotation as shown in Figure 4. The variation on pitch does also effects the position of aerodynamic center of

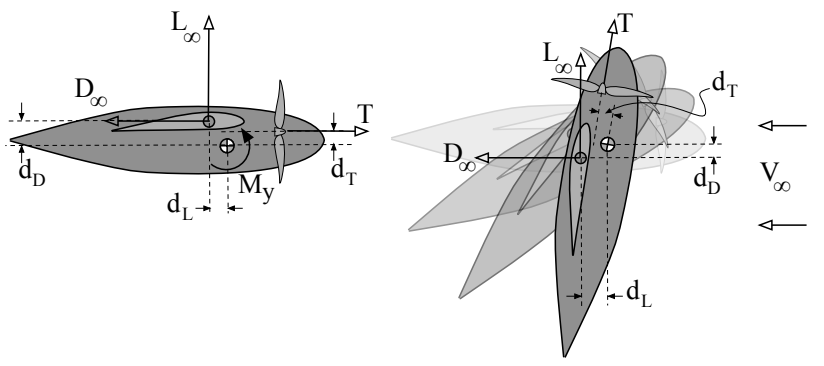

Figure 4. Illustration of the moment arm length variation during pitch attitude change.

the wing as experimentally tested by Draper and Kuhn. ${ }^{3}$ However we will assume it to be fixed. The thrust moment arm $d_{T_{j}}$ does not change during the pitch variation. However lift force moment arm $d_{L}$ and drag force moment arm $d_{D}$ has to be calculated at every angle of attack as a result of moment arm length variation. Finally, the total pitching moment of the aircraft is found by

$$
M_{y}=M_{\text {wing }_{A C}}-\sum_{j e t s} T_{j} d_{T_{j}}-L_{\infty} d_{L}+D_{\infty} d_{D}
$$




\section{Experimental Comparison}

Explained method is parametrized in order to accept multi-variable input, such as the number of propellers, diameter, pitch, position and orientations, wing surface, different thrusts, etc... and written into a FORTRAN code. The final program is capable of analyzing any given configuration within the explained limitations. Comparison of the program with experimental measurements, and with other reliable numerical simulations is a must. Therefore, two comparison with NASA experiments are used as a test case. Further comparisons, with LEAPTech blown wing, both numerical simulations and experimental measurements are in progress.

\section{A. Comparison with NASA TN3307 Report}

Experimental measurements are digitized by using the original report obtained from NASA Technical Report Service. The test case presented here is a two engined configuration, with a $+20 \mathrm{deg}$ flap. The general specifications of the test model is represented in Table 1. Two different cases are simulated, with thrust coefficient $C_{T}=0.5$

and $C_{T}=0.91$. Lift coefficient $C_{L}$ versus angle of attack $\alpha$ variation, and drag coefficient $C_{D}$ is plotted respectively which are

\begin{tabular}{lcl}
\hline Wing Span & 4.16 & {$[\mathrm{~m}]$} \\
Wing Surface Area & 0.952 & {$\left[\mathrm{~m}^{2}\right]$} \\
Mean Aero. Chord & 0.457 & {$[\mathrm{~m}]$} \\
Prop Diameter & 0.61 & {$[\mathrm{~m}]$} \\
Section Airfoil & NACA0015 & \\
Section $\alpha_{C_{L \max }}$ & 14.0 & {$[-]$} \\
\hline
\end{tabular}

Table 1. General specifications of the TN-3307 wind-tunnel model. shown in Figure 5. The correlation between the theory and the experimental measurements shows an acceptable relation, especially on the $C_{T}=0.91$ case. However there are still some problems to be solved (mainly on the code) for the drag contribution when the wing is partially stalled.

Aerodynamic coefficients shown in the Figure 5 refers to the propeller slipstream velocity instead of freestream velocity as some of the experimental measurements done in static conditions where the freestream velocity is equal to zero. The drag coefficients shown, are calculated including the propeller thrust contribution too as the wing and the propellers work together in the system. The negative drag coefficients results from excessive amount of thrust contribution. The lift curve behavior is well estimated with the semi empirical theory. After the sharp high lift portion of the first lift curve $\left(C_{T}=0.5\right)$, the estimations mismatch the experiment, and the drag coefficient of that case also have a huge error, which is still under investigation. 

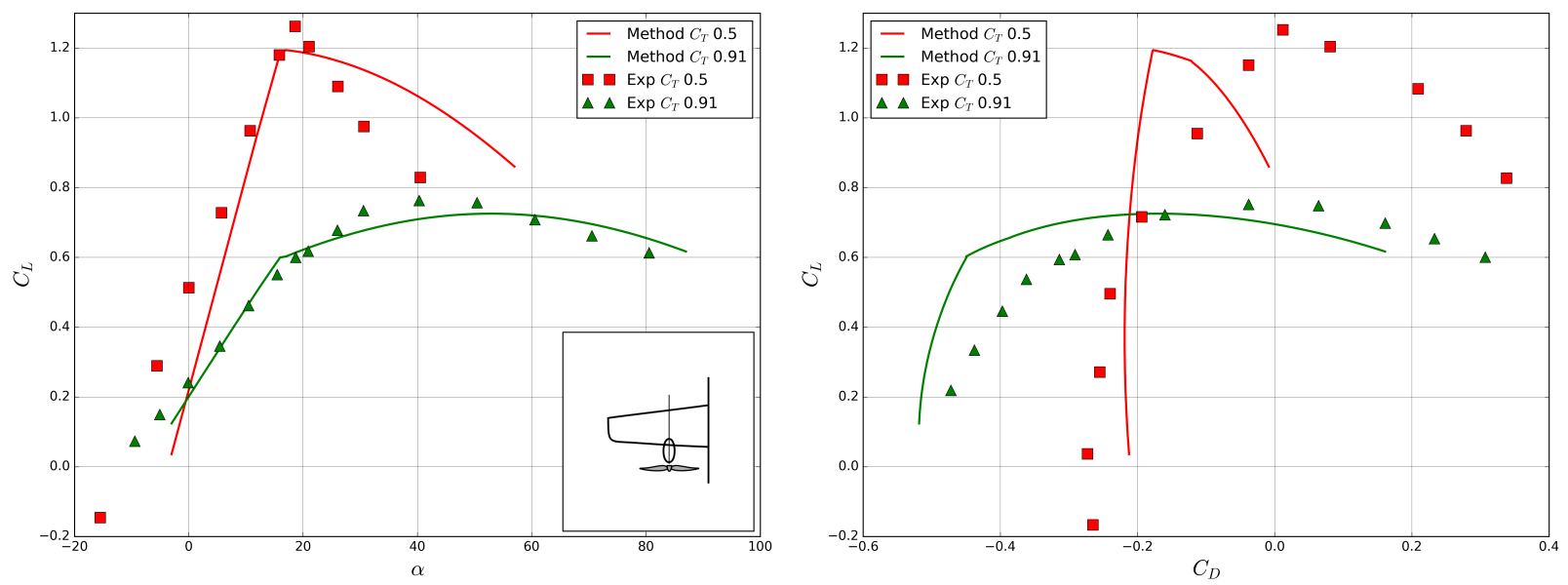

Figure 5. Theory and experimental measurement correlation is shown for TN-3307, where the reference velocity is taken from the propeller slipstream velocity.

\section{B. Comparison with NASA TN-D-4448 Report}

Another experimental comparison is selected to be done with a four propeller wing from NASA TN-D-4448 Report. The general specifications of the test model is represented in Table 2. Two test case is examined, with thrust coefficient $C_{T}=0$ and $C_{T}=0.856$. Likewise, the lift coefficient $C_{L}$ versus angle of attack $\alpha$ variation, and drag coefficient $C_{D}$ is plotted respectively which are shown in Figure 6. There is no flap deflection on the wind-tunnel model, however the wing section airfoil camber is represented

\begin{tabular}{lcl}
\hline Wing Span & 13.19 & {$[\mathrm{~m}]$} \\
Wing Surface Area & 30.56 & {$\left[\mathrm{~m}^{2}\right]$} \\
Mean Aero. Chord & 2.31 & {$[\mathrm{~m}]$} \\
Prop Diameter & 2.83 & {$[\mathrm{~m}]$} \\
Fuselage Diameter & 0.91 & {$[\mathrm{~m}]$} \\
Section Airfoil & NACA63 416 & \\
Section $\alpha_{C_{L \max }}$ & 16.0 & {$[-]$} \\
\hline
\end{tabular}

Table 2. General specifications of the TN-D-4448 wind-tunnel model. by flap deflection for the theoretical calculations. Lift curve slope match is visible for the two cases, however there is still some problems with the drag estimation.

\section{Conclusion}

A brief description of the semi-empirical method for estimating force and moments generated by a wing partially or fully immersed inside distributed propeller slipstream is given. The results obtained by the method is compared with experimental measurements coming from NASA TN3307 ${ }^{2}$ and TN-D-4448 ${ }^{1}$ reports for verification purpose. The wing configurations are simulated by the proposed method and comparison are shown. The program is capable of estimating the lift curve correctly, which will be useful during the conceptual design phase, however there is still some mismatch on the drag force estimations. Further verifications will 

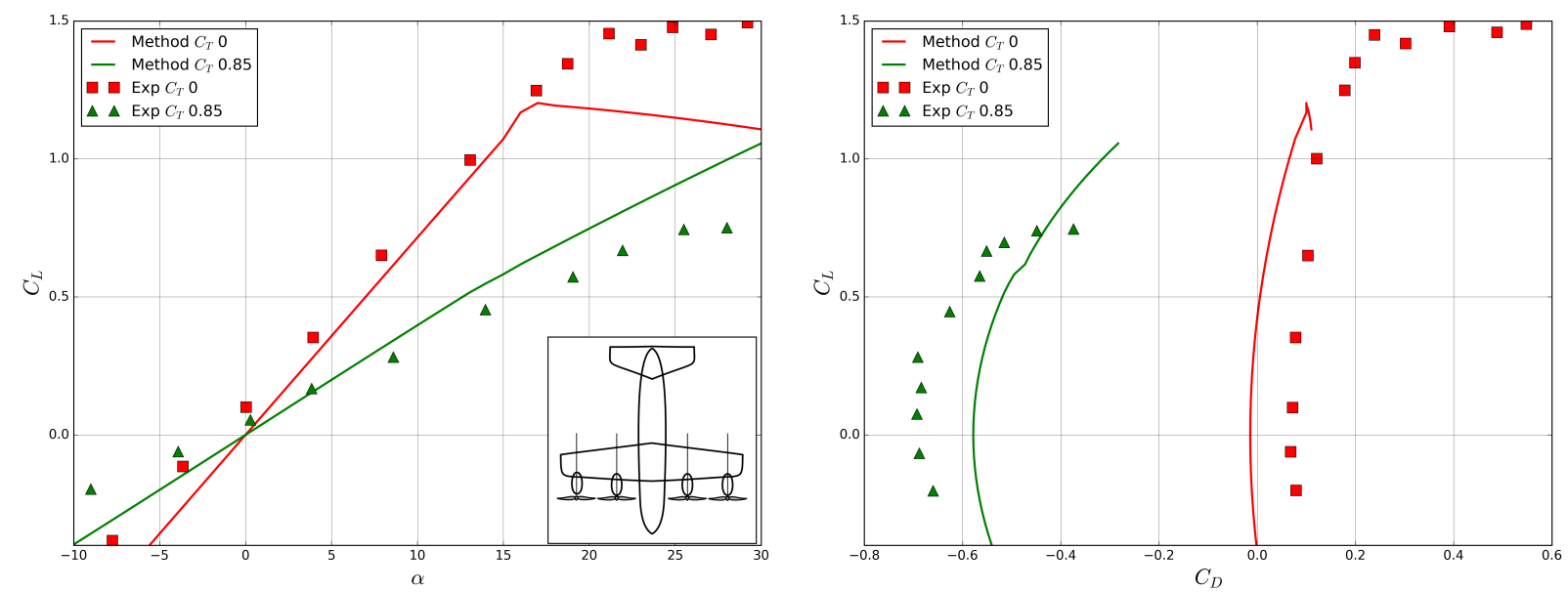

Figure 6. Theory and experimental measurement correlation is shown for TN-D-4448, where the reference velocity is taken from the propeller slipstream velocity.

continue as a future work through additional comparison with experimental measurements and numerical (such as CFD) simulations.

\section{Acknowledgments}

The authors would like to thank Alex Stoll of JobyAviation for sharing the geometrical and aerodynamic specifications of the LEAPTech demonstrator wing with simulated results and experimental measurements. However, the authors have not finish the analyses therefore the results are not presented on the paper.

\section{References}

${ }^{1}$ Deckert, W. H. Dickinson, S. O. P. V. R., "Large-scale wind-tunnel tests of a deflected slipstream STOL model with wings of various aspect ratios," Tech. Rep. NASA-TN-D-4448, NASA Ames Research Center, Moffett Field, CA, United States, 01 March 1968, ID:19680009302.

${ }^{2}$ Kuhn, R. E. and Draper, J. W., "An investigation of a wing-propeller configuration employing largechord plain flaps and large-diameter propellers for low-speed flight and vertical take-off," Tech. Rep. NASATN-3307, National Advisory Committee for Aeronautics. Langley Aeronautical Lab., Langley Field, VA, United States, 01 December 1954, ID:19930084052.

${ }^{3}$ Draper, J. W. and Kuhn, R. E., "Investigation of the Aerodynamic Characteristics of a model wingpropeller combination and of the wing and Propeller Separately at Angles of Attack up to 90 degrees," Tech. Rep. NACA-TN-3304, National Advisory Committee for Aeronautics. Langley Aeronautical Lab., Langley Field, VA, United States, November 1954, ID:19930092264.

${ }^{4}$ Moore, M. D. and Fredericks, B., "Misconceptions of Electric Propulsion Aircraft and their Emergent Aviation Markets," the 52nd Aerospace Sciences Meeting AIAA SciTech, 17p, 2014.

${ }^{5}$ Stoll, A. M., Bevirt, J., Moore, M. D., Fredericks, W. J., and Borer, N. K., "Drag Reduction Through Distributed Electric Propulsion," Aviation Technology, Integration, and Operations Conference, Atlanta, Georgia, 16-20 June 2014. 
${ }^{6}$ Jameson, A., "The Analysis of Propeller Wing Flow Interaction, Analytic Methods in Aircraft Aerodynamics," NASA Symposium Proceedings SP-228, October 1969, pp. 721-749.

${ }^{7}$ De Young, J., "Propellers at High Incidence," Journal of Aircraft, Vol. 2, No. 3, May-June 1965, pp. pp $241-250$.

${ }^{8}$ Bronz, M. and Drouin, A., "Preliminary Design Estimation of the V/STOL Airplane Performance," IMAV 2015, International Micro Air Vehicles Conference and Flight Competition, Aachen, September 2015.

${ }^{9}$ Ribner, H. S., "Notes on the Propeller Slipstream in Relation to Stability," NACA ARR L4112a (WRL25), 1944. 